
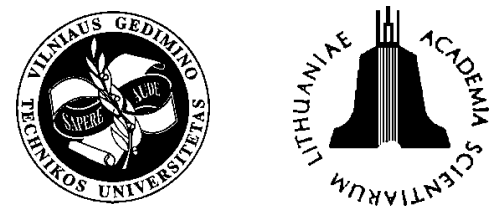

JOURNAL OF CIVIL ENGINEERING AND
http:/www.vtu.lt/english/editions

2004, Vol X, No 3, 227-233

\title{
DILATANCY OF CEMENT SLURRIES WITH CHEMICAL ADMIXTURES
}

\author{
Gintautas Skripkiūnas', Mindaugas Daukšys ${ }^{2}$ \\ Dept of Building Materials, Kaunas University of Technology, Studentu g. 48, LT-51367 Kaunas, Lithuania. \\ ${ }^{1}$ E-mail: Gintautas.Skripkiunas@ktu.lt; ${ }^{2} E$-mail: Mindaugas.Dauksys@ktu.lt
}

Received 21 March 2004; accepted 7 June 2004

\begin{abstract}
The results of experimental investigation of plasticising, air-entraining and viscosity-modifying admixtures with different chemical composition influence on rheological properties and dilatancy of cement slurries are presented in the article. Rheological properties of cement slurries were tested by a rotation viscometer with coaxial cylinder, at different gradients of velocity. Dilatancy of cement slurries was determined by the distortion of the rheological curve and index of dilatancy D was calculated according to proposed methods. The results of investigation show that the properties of liquid disperse medium of structural system influence slightly the dilatancy of cement slurries. Plasticising admixtures with a different chemical composition slightly increases but air-entraining and viscosity-modifying admixtures slightly reduces the dilatancy of cement slurries.
\end{abstract}

Keywords: cement slurry, chemical admixtures, rheology, yield stress, viscosity, dilatancy, viscometer.

\section{Introduction}

Cement slurries are among the so-called structural systems that have certain rheological properties. According to the shape of the rheological curve structural systems are divided into some groups: Newtonian fluid, pseudoplastic fluid, dilatantic fluid, Bingham fluid, plastically dilatantic body and pseudoplastic body $[1,2]$. Graphical expression of shear rate dependency upon shear stress $\bar{\gamma}$ is called flow curve (Fig 1).

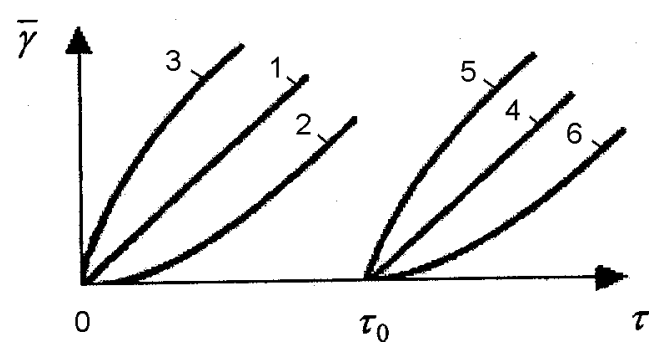

Fig 1. Flow curves of different structural systems: 1 Newtonian fluid; 2 - pseudoplastic fluid; 3 - dilatantic fluid; 4 - Bingham fluid; 5 - plastically dilatantic body; 6 - pseudoplastic body

Cement slurries and concrete mixtures are usually defined as Bingham fluids (systems); they have two main rheological characteristics - yield stress $\tau_{0}$ and plastic viscosity $\eta[3-5]$.
The dilatant behaviour increases the viscosity of cement slurries with the increasing shear stress. The dilatancy has negative influence on cement slurries and concrete mixtures pumping by concrete pumps. Various chemical admixtures were tested to change rheological properties and to reduce dilatancy of cement slurries for improving concrete pumping.

\section{Literature review}

Chemical admixtures are often used for modification of rheologic properties of fresh concrete. Plasticizing and superplasticising admixtures with different chemical composition are used for changing rheologic properties of concrete mixtures [6,7]. Chemical composition of admixture influences the plasticising effect of admixtures $[8,9]$. Rheologic properties of concrete mixtures are influenced by air-entraining admixtures that are used for increasing freezing-thawing resistance of hardened concrete. The use of viscosity-enhancing admixtures increases the homogeneity of cement slurries and concrete mixtures and leads to a greater uniformity of hardened properties. These admixtures greatly influence the thixotropy of concrete mixtures $[10,11]$. Viscosity-enhancing admixtures are used for increasing flowability of concrete using concrete pumps.

For testing the rheologic properties of cement slurries and concrete mixtures different viscometers are applied [12-14]. Comparing results obtained by viscometers with coaxial cylinders of different dimensions, the 
influence of geometrical dimensions on the results of rheologic properties testing was observed [15]. Fresh concrete rheologic properties tested with different type viscometers show some differences in viscosity testing results [16]. Therefore some investigators propose to use the relative plastic viscosity instead of plastic viscosity for comparing the results obtained with different viscometers [17]. The proposed relative plastic viscosity of fresh concrete is the ratio of viscosity of concrete mixture to the viscosity of mortar or matrix. It eliminates the influence of geometrical parameters of equipment on test results.

New testing methods show the influence of mixing on the rheologic properties of cement slurries [18]. The hysteresis loop was observed from shear-induced structural breakdown in cement paste. Plastic viscosity in this investigation was determined using the slope of the hysteresis down curve on the range of shear rates in some limits. It was determined in this investigation that mixtures obtained in high shear mixer are more flowable.

Cement slurries and concrete mixture testing results demonstrate that Bingham model is not correct for describing the cement slurries flow. Flow curves of cement slurries are not straight lines like in the Bingham model but with the increasing of shear stress they became the distort lines [19-21]. The distortion of flow curve indicates the dilatancy of cement slurries, ie the viscosity of system is increasing with the shear stress increase. There are no characteristics for quantitative estimation of dilatancy of mixtures.

The first investigation into dilatancy phenomenon was carried out by O. Reynolds. According to the author, the increase of system viscosity can be explained by the increase of disperse system volume after the change of solid particles volume displacement caused by the movement of particles to each other. The disperse system volume increase causes the relative decrease of disperse medium volume and the increase of system viscosity [22]. In Fig 2 spheric solid particles have the pyramidic volume distribution (left) and the cubic one (right). Solid pyramidic particles distribution take up a minimum volume. After affect of shear force the volume distribution of solid particles can be changed to cubic distribution that will increase the volume occupied by solid particles by 1,41 time.

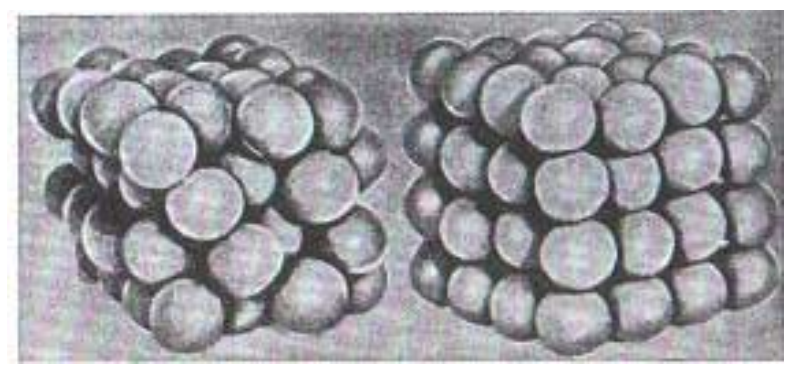

Fig 2. Volume change of spheric particles system caused by shear force (pyramidic distribution on the left; cubic distribution on the right)
F. S. Kaplan, J. E. Pivinskij and A. N. Saprykin investigate rheological properties and dilatancy of quartz glass suspensions [23]. They have noted that dilatancy is observed in high-concentration disperse systems and proposed a rheological equation for dilatant fluids:

$$
\tau=\eta \cdot \gamma^{-n}
$$

where $\tau$ - shear stress; $\bar{\gamma}$ - shear rate; $\eta$ - plastic viscosity; $n$ - degree of dilatancy.

For Newtonian fluid $n=1$, for dilatant fluid $n>1$, for pseudoplastic fluid $\mathrm{n}<1$. This investigation shows a great influence of liquid phase $\mathrm{pH}$ on dilatancy of suspension [23]. The degree of dilatancy depends on solid particles concentration, shape and dimensions of particles, viscosity and composition of disperse medium [23].

In the investigation the superplasticisers effects on viscosity and yield stress of cement mixtures K. Asaga and D. M. Roy found that dilatant behaviour is observed in all cases with sulphonated naphthalene and melamine formaline condensates admixtures concentrations higher than $0,75 \%$ [6]. Investigation of superplasticised cement pastes containing mineral additives carried out by $\mathrm{F}$. Curcio and B. A. DeAngelis show that dilatant behaviour is strongly dependent on the water/binder ratio, on the level of cement replacement by mineral additives and on the fineness of the latter. Dilatancy is caused by angular and platelike particles [24].

$\mathrm{Ch}$. Hu and F. de Larrard determined that dilatancy is related to the tested material and testing method. Any relationship does not exist between the dilatancy and the Bingham characteristics - yield stress and plastic viscosity [14]. V. Ukraincik defined that the phenomena of shear thickening and thinning obtained on flow curves can partly be explained as being due to dilatancy and to related changes in the fluid phase to pore air ratio in fresh concrete. Shear-box tests with simple shear have shown the proportionality of the dilatancy to the square of shear stress [25].

\section{Experimental procedure}

The experimental investigation was carried out to determine the dilatancy of cement slurries and influence of chemical admixtures on it. Plasticising, air-entraining and viscosity-modifying admixtures were tested. Yield stress and viscosity of cement slurries were determined and dilatancy was estimated by the distortion of flow curve.

Cement slurries were mixed by hands for $5 \mathrm{~min}$. All slurries were prepared with the same $\mathrm{W} / \mathrm{C}$ ratio $(0,55)$. Plasticising admixtures were mixed with water, used for slurries preparing. Air-entraining admixtures were added separately after slurries mixing. Total amount of admixtures was in the range from 0,2 to $1,0 \%$ of cement mass.

In this investigation Portland cement CEM I 42,5 produced by the AB "Akmenès cementas" was used. 
Water requirement for normal consistency of cement slurry was $27,5 \%$, the specific surface of cement particles $353 \mathrm{~m}^{2} / \mathrm{kg}$, the cement particles density $3110 \mathrm{~kg} / \mathrm{m}^{3}$.

Plasticising admixtures used: plasticiser SMR based on lignosulphonates, solution density $1,14 \mathrm{~kg} / \mathrm{l}$; superplasticiser Glenium 127 based on polycarboxyl polymers, the solution density $1,10 \mathrm{~kg} / \mathrm{l}$. Air-entraining admixture Amex SB 22 (LP) made of liquid surface tension increasing materials, was used, the solution density $1,01 \mathrm{~kg} / \mathrm{l}$. Starvis $2006 \mathrm{~L}$ was used as viscosity-modifying admixture (synthetic polymers with a big molecular mass, the solution density $1,01 \mathrm{~kg} / \mathrm{l}$ ).

Rheologic properties of cement slurries were tested with rotational viscometer $\mathrm{BCH}-3$ (Fig 3).

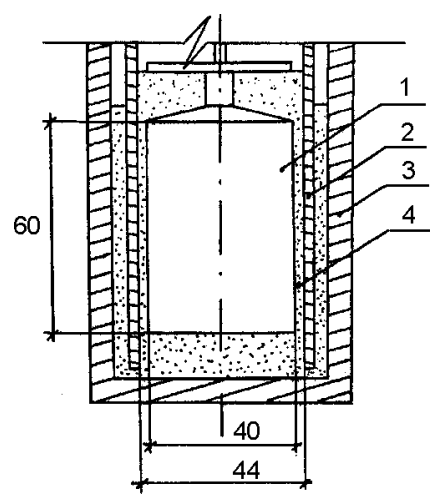

Fig 3. Scheme of rotational viscometer with coaxial cylinders: 1 - cylinder connected with measuring scale; 2 internal (rotating) cylinder; 3 - external (fixed) cylinder; 4 - cement slurry

The cement slurry was poured into the cylindrical vessel (3) (external cylinder) fixed to the viscometer. Internal cylinder (2) was rotated in the external cylinder with the slurry. The friction between the rotating internal cylinder and the cylinder, which is inside it (1) and connected to the measuring scale turns internal cylinder (1) connected to the measuring scale due to cement slurry (4) inside friction.

Viscosity of cement slurry was estimated using different internal cylinder rotation rates $(600,400,300,200$ $1 / \mathrm{min})$. Shear force $\mathrm{F}(\mathrm{mN})$ which turns cylinder connected to the measuring scale, was calculated by the measuring scale readings using the calibration line. Such lines were evaluated experimentally and depend on the elasticity of the springs in the device. A more elastic spring is suitable for measuring viscosity of cement slurries with low $\mathrm{W} / \mathrm{C}$ ratio, when there are bigger shear stresses.

Shear rate $\bar{\gamma}$ for the different rotation rate of the cylinder (2) was calculated by the equation (2):

$$
\bar{\gamma}_{i}=\frac{2 \pi \cdot r \cdot n_{i}}{d_{s}}, s^{-1} \text {, }
$$

where $r$ - radius of the cylinder connected to the measuring scale, $\mathrm{m} ; n_{i}$ - rotation rate of the internal cylinder $(i=\overline{1,4}), 1 / \mathrm{s} ; d_{s}$ - distance between (1) and (2) cylinders, $\mathrm{m}$.

Shear stress of cement slurry $\tau$ for different shear rates was calculated by equation (3):

$$
\tau_{i}=\frac{F_{i}}{2 \pi \cdot r \cdot h}, P a,
$$

where $F_{i}$ - shear force calculated by the readings in measuring scale using calibration line, $\mathrm{mN} ; r$ and $h-$ radius and height of the cylinder connected to the measuring scale, $\mathrm{m}$.

Viscosity of cement slurries $\eta$ for the different shear rates was calculated by the (4) equation:

$$
\eta_{i}=\frac{\tau_{i}-\tau_{0}}{\gamma_{i}}, P a \cdot s,
$$

where $\tau_{0}$ - yield stress, determined by $\bar{\gamma}-\tau$ curve point were the curve cross the $\tau$ axis.

\section{Experimental results}

Flow curves of cement slurries (W/C ratio 0,55 ) without and with chemical admixtures dosage $0,2 \%$ of the cement mass are presented in Fig 4.

Fig 4 curves in show that the superplasticizer based on polycarboxyl polymers the biggest reduction effect on yield stress of cement slurries (about $65 \%$ in comparison with cement slurry without admixture) produces when used in the dosage $0,2 \%$ of cement mass.

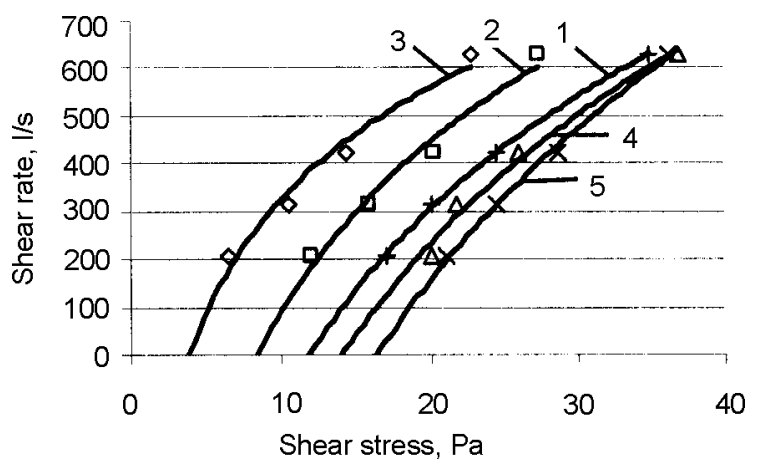

Fig 4. Flow curves of cement slurries with chemical admixtures dosage $0,2 \%$ of the cement mass: 1 - without admixture; 2 - with plasticiser (lignosulphonates); 3 - with superplasticiser (polycarboxyl polymers); 4 - with air-entraining admixture; 5 - with viscosity-modifying admixture (synthetic polymers with big molecular mass)

Less efficient in yield stress reduction is a plasticiser on the base of lignosulphonates (about $30 \%$ in comparison with cement slurry without admixture). Air-entraining admixture opposite to plasticising admixtures increases the yield stress of cement slurry. Viscositymodifying admixture increases the yield stress of cement 
Table 1. Yield stress and viscosity of cement slurries

\begin{tabular}{|c|c|c|c|c|c|c|c|}
\hline \multirow{2}{*}{ Composition of cement slurry } & \multirow{2}{*}{$\begin{array}{c}\text { Dosage of } \\
\text { admixture, } \%\end{array}$} & \multirow[t]{2}{*}{ Viscosity } & \multicolumn{4}{|c|}{ Shear rate $\bar{\gamma}, 1 / \mathrm{s}$} & \multirow{2}{*}{$\tau_{0}, \mathrm{~Pa}$} \\
\hline & & & 205 & 315 & 420 & 630 & \\
\hline $\mathrm{W} / \mathrm{C}=0,55$ without admixture & - & $\eta_{i}, \mathrm{~Pa} \cdot \mathrm{s}$ & 0,0245 & 0,0256 & 0,0296 & 0,0363 & 12,00 \\
\hline \multirow{4}{*}{$\begin{array}{l}\mathrm{W} / \mathrm{C}=0,55 \\
\text { with plasticiser }\end{array}$} & $0,20 \%$ & \multirow{4}{*}{$\eta_{i}, \mathrm{~Pa} \cdot \mathrm{s}$} & 0,0180 & 0,0242 & 0,0285 & 0,0300 & 8,33 \\
\hline & $0,40 \%$ & & 0,0155 & 0,0225 & 0,0257 & 0,0282 & 6,67 \\
\hline & $0,60 \%$ & & 0,0147 & 0,0213 & 0,0253 & 0,0276 & 5,74 \\
\hline & $1,00 \%$ & & 0,0128 & 0,0201 & 0,0229 & 0,0249 & 4,81 \\
\hline \multirow{4}{*}{$\begin{array}{c}\mathrm{W} / \mathrm{C}=0,55 \\
\text { with superplasticser }\end{array}$} & $0,20 \%$ & \multirow{4}{*}{$\eta_{\mathrm{i}}, \mathrm{Pa} \cdot \mathrm{s}$} & 0,0129 & 0,0208 & 0,0250 & 0,0298 & 3,93 \\
\hline & $0,40 \%$ & & 0,0109 & 0,0174 & 0,0235 & 0,0274 & 3,04 \\
\hline & $0,60 \%$ & & 0,0091 & 0,0170 & 0,0210 & 0,0251 & 2,32 \\
\hline & $1,00 \%$ & & 0,0070 & 0,0143 & 0,0180 & 0,0220 & 1,43 \\
\hline \multirow{4}{*}{$\begin{array}{l}\mathrm{W} / \mathrm{C}=0,55 \\
\text { with air-entraining admixture }\end{array}$} & $0,20 \%$ & \multirow{4}{*}{$\eta_{\mathrm{i}}, \mathrm{Pa} \cdot \mathrm{s}$} & 0,0289 & 0,0243 & 0,0281 & 0,0360 & 14,14 \\
\hline & $0,40 \%$ & & 0,0240 & 0,0267 & 0,0309 & 0,0365 & 11,44 \\
\hline & $0,60 \%$ & & 0,0219 & 0,0232 & 0,0262 & 0,0330 & 9,70 \\
\hline & $1,00 \%$ & & 0,0252 & 0,0233 & 0,0247 & 0,0331 & 12,08 \\
\hline \multirow{4}{*}{$\begin{array}{l}\mathrm{W} / \mathrm{C}=0,55 \\
\text { with viscosity-modifying admixture }\end{array}$} & $0,20 \%$ & \multirow{4}{*}{$\eta_{\mathrm{i}}, \mathrm{Pa} \cdot \mathrm{s}$} & 0,0232 & 0,0255 & 0,0290 & 0,0314 & 16,40 \\
\hline & $0,40 \%$ & & 0,0246 & 0,0264 & 0,0291 & 0,0326 & 17,85 \\
\hline & $0,60 \%$ & & 0,0224 & 0,0257 & 0,0265 & 0,0301 & 17,65 \\
\hline & $1,00 \%$ & & 0,0218 & 0,0246 & 0,0262 & 0,0296 & 16,25 \\
\hline
\end{tabular}

slurry more than air-entraining admixture. Yield stress increasing makes mixtures more stable, ie reduces sedimentation of aggregates and water bleeding in mixtures. Superplasticiser and plasticiser insignificantly reduce viscosity of cement slurry (Table 1). Air-entraining admixture increases the viscosity of cement slurry (Table 1).

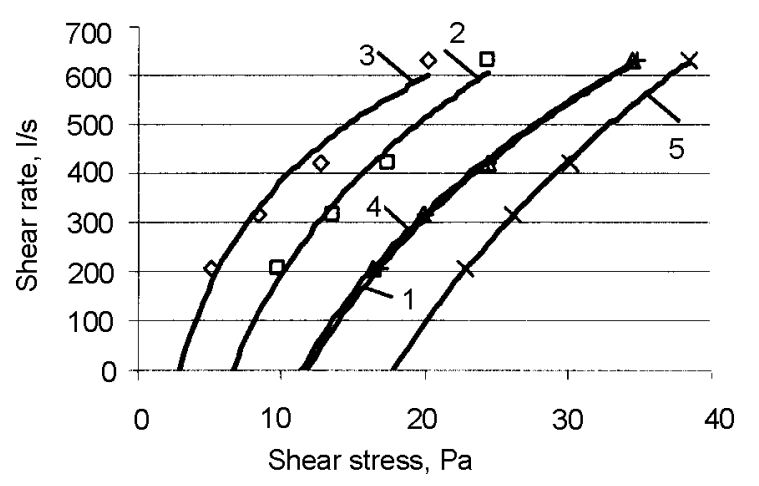

Fig 5. Flow curves of cement slurries with chemical admixtures dosage of $0,4 \%$ of cement mass: 1 - without admixture; 2 - with plasticiser (lignosulphonates); 3 - with superplasticiser (polycarboxyl polymers); 4 - with air-entraining admixture; 5 - with viscosity-modifying admixture (synthetic polymers with a big molecular mass)

The dependence of shear rate on the shear stress for the cement slurries without and with chemical admixtures dosage of $0,4 \%$ of the cement mass are presented in Fig 5. Superplasticiser and plasticiser in the dosage of $0,4 \%$ of the cement mass reduces yield stress of cement slurry more efficient than in a less dosage (about $45 \%$ and $75 \%$ correspondingly) (Fig 5) and reduces viscosity of cement slurry more than in the less dosage (Table 1). Dosage of air-entraining admixture of $0,4 \%$ of the cement mass has no effect on the yield stress and viscosity of cement slurry compared with cement slurry with no admixture. An increase of viscosity-modifying admixture dosage to of $0,4 \%$ of cement mass more increases the yield stress of cement slurry than less dosages of this admixture (Fig 5).

Flow curves of cement slurries with chemical admixtures dosages of $0,6 \%$ and $1,0 \%$ of mass cement are presented in the Figs 6 and 7 .

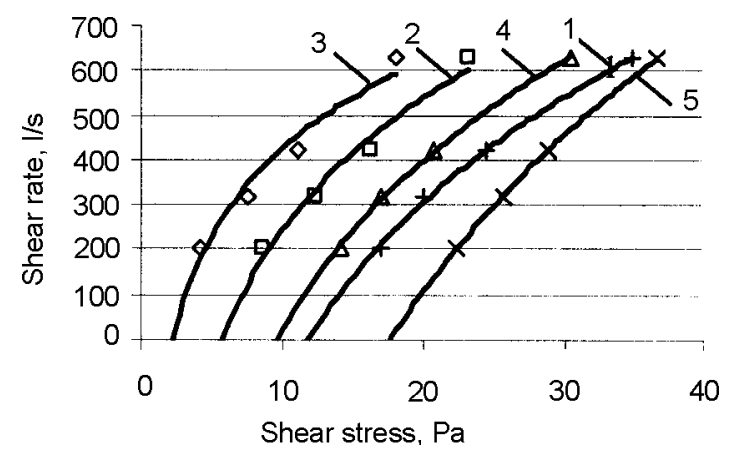

Fig 6. Flow curves of cement slurries with chemical admixtures dosage of $0,6 \%$ of cement mass: 1 - without admixture; 2 - with plasticiser (lignosulphonates); 3 - with superplasticiser (polycarboxyl polymers); 4 - with air-entraining admixture; 5 - with viscosity-modifying admixture (synthetic polymers with a big molecular mass)

Figs 6 and 7 show that with an increase of plasticiser and superplasticiser dosage yield stress of cement slurry decreases. Effect of big dosages (0,6 and 1,0\% of the cement mass) of air-entraining and viscosity-modifying admixtures on yield stress and viscosity of cement slurries is similar to the effect of $0,4 \%$ dosage of these admixtures.

Plasticisers and superplasticisers change the dilatancy of cement slurry. This can be seen $b$ increasing the distortion of the flow curves (Figs 4-7). Viscosity-modify- 


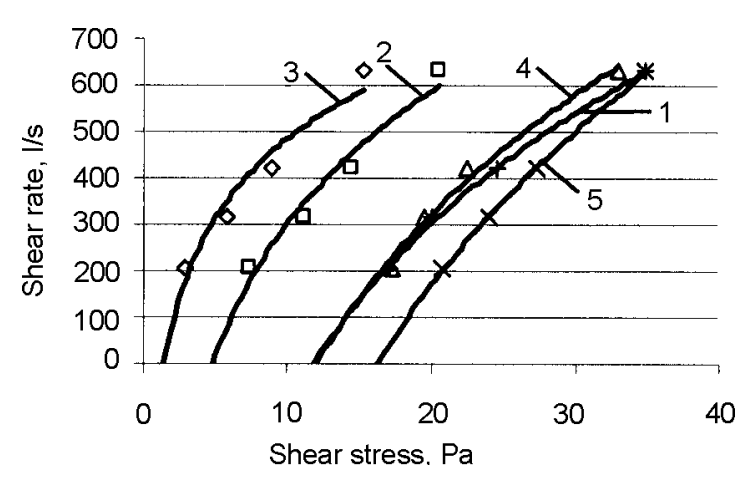

Fig 7. Flow curves of cement slurries with chemical admixtures of $1,0 \%$ of cement mass: 1 - without admixture; 2 - with plasticiser (lignosulphonates); 3 - with a superplasticiser (polycarboxyl polymers); 4 - with air-entraining admixture; 5 - with viscosity-modifying admixture (synthetic polymers with a big molecular mass)

ing admixture has the opposite effect on the cement slurry dilatancy. The flow curves of cement slurry with this admixture are similar to the straight lines.

The influence of dosage of different chemical admixtures on yield stress of cement slurry with $\mathrm{W} / \mathrm{C}$ ratio 0,55 is presented in Fig 8.

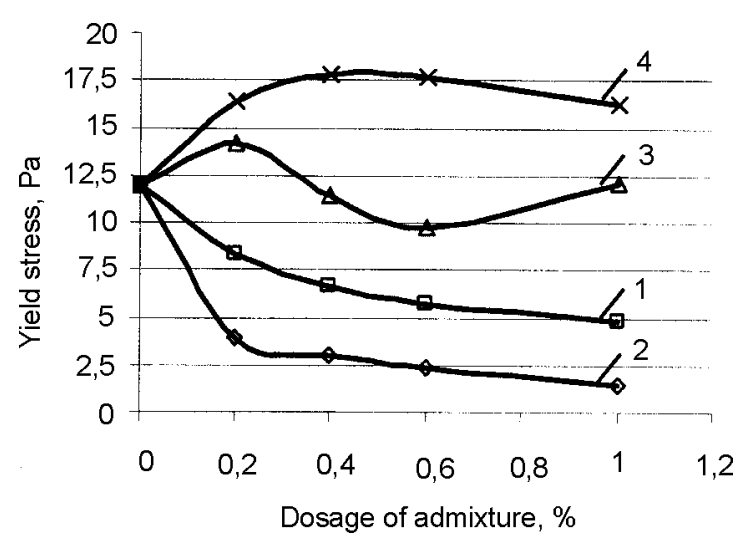

Fig 8. Influence of dosage of chemical admixtures on yield stress of cement slurry: 1 - with plasticiser (lignosulphonates); 2 - with superplasticiser (polycarboxyl polymers); 3 - with air-entraining admixture; 4 - with viscosity-modifying admixture (synthetic polymers with a big molecular mass)

The results plotted in Fig 8 show that a superplasticiser on the base of polycarboxyl polymers more effectively by reduces the yield stress of cement slurry with increasing the admixture dosage. Big dosages $(1,0 \%$ and more) of this admixture reduce yield stress of cement slurry almost to zero. The effect of a plasticiser on the base of lignosulphonates dosage is the same like a superplasticiser but with a less reduction of yield stress of cement slurry. Small dosages (up to $0,2 \%$ of cement mass) of these admixtures more effective by reduce yield stress of cement slurry than the largest dosages. An air- entraining admixture has no significant effect on yield stress of cement slurry, but small dosages of this admixture $(0,2 \%)$ show little increase in cement slurry yield stress. Viscosity-modifying admixture on the base of synthetic polymers with a big molecular mass increases the yield stress of cement slurry in dosages up to $0,4 \%$ and keep it stable in dosages above $0,4 \%$ of the cement mass.

The influence of dosage of different admixtures on viscosity of cement slurry tested at $205 \mathrm{1} / \mathrm{s}$ shear rate is presented in Fig 9.

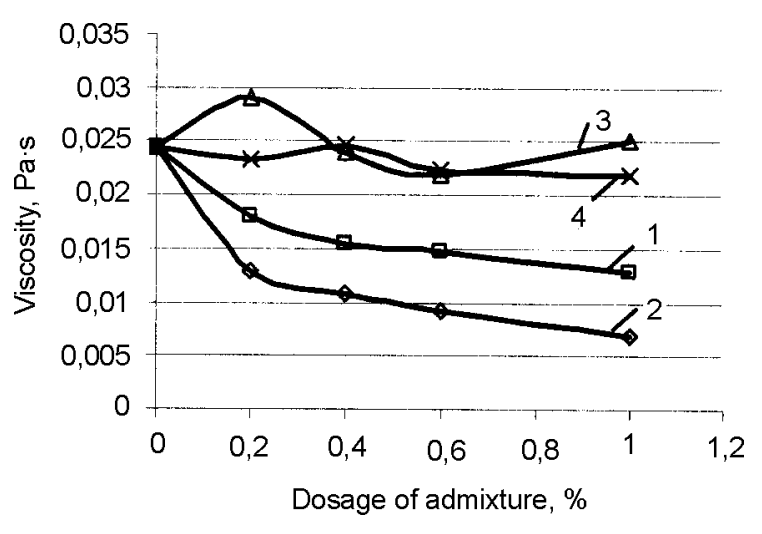

Fig 9. Influence of dosage of chemical admixtures on viscosity of cement slurry tested at $2051 / \mathrm{s}$ shear rate: 1 with plasticiser (lignosulphonates); 2 - with superplasticiser (polycarboxyl polymers); 3 - with air-entraining admixture; 4 - with viscosity-modifying admixture (synthetic polymers with a big molecular mass)

A superplasticizer on the base of polycarboxyl polymers and plasticizer on the base of lignosulphonates reduces the viscosity of cement slurry in the small range with increasing the admixture dosage. Superplasticizers are more efficient in reduction of viscosity of cement slurry than plasticizers. An air-entraining admixture negligibly increases the cement slurry viscosity in the range of dosage up to $0,2 \%$ from the cement mass and has no effect on viscosity with later increasing the dosage. Viscosity-modifying admixture has no significant effect on viscosity of cement slurry in the range of all used dosages.

For the evaluation of dilatancy of cement slurries the index $D$ was proposed. Index of dilatancy $D$ was calculated by the equation (5):

$$
D=\frac{\Delta \eta}{\Delta \tau}, \frac{P a \cdot s}{P a},
$$

where $\Delta \eta$ - the change of the viscosity (Pa.s) of cement slurry at shear rates $630 \mathrm{1} / \mathrm{s}$ and $205 \mathrm{1} / \mathrm{s}$ :

$$
\Delta \eta=\eta_{630}-\eta_{205}, P a \cdot s,
$$

$\Delta \tau$ is the change of the shear stress (Pa) of cement slurry at shear rates $6301 / \mathrm{s}$ and $2051 / \mathrm{s}$ :

$$
\Delta \tau=\tau_{630}-\tau_{205}, P a .
$$


The dilatancy index $D$ for the cement slurries with different quantity of the admixtures is presented in Table 2 .

Table 2. Index of dilatancy $D$ of cement slurries with different admixture

\begin{tabular}{c|c|c}
\hline $\begin{array}{c}\text { Composition of cement } \\
\text { slurry }\end{array}$ & $\begin{array}{c}\text { Dosage of } \\
\text { admixture, } \\
\%\end{array}$ & $\begin{array}{c}\mathrm{D} \times 10^{-3}, \\
\mathrm{~Pa} \cdot \mathrm{s} / \mathrm{Pa}\end{array}$ \\
\hline $\begin{array}{c}\mathrm{W} / \mathrm{C}=0,55 \\
\text { without admixture }\end{array}$ & - & 0,660 \\
\hline \multirow{3}{*}{$\begin{array}{c}\mathrm{W} / \mathrm{C}=0,55 \\
\text { with plasticiser }\end{array}$} & $0,20 \%$ & 0,787 \\
\cline { 2 - 3 } & $0,40 \%$ & 0,870 \\
\cline { 2 - 3 } & $0,60 \%$ & 0,898 \\
\hline \multirow{2}{*}{$\begin{array}{c}\mathrm{W} / \mathrm{C}=0,55 \\
\text { with superplasticiser }\end{array}$} & $1,00 \%$ & 0,926 \\
\cline { 2 - 3 } & $0,20 \%$ & 1,049 \\
\cline { 2 - 3 } & $0,40 \%$ & 1,098 \\
\cline { 2 - 3 } W/C $=0,55$ & $1,00 \%$ & 1,149 \\
\hline with air-entraining & $0,20 \%$ & 1,209 \\
\cline { 2 - 3 } admixture & $0,40 \%$ & 0,424 \\
\cline { 2 - 3 } & $0,60 \%$ & 0,692 \\
\cline { 2 - 3 } W/C $=0,55$ & $1,00 \%$ & 0,504 \\
\hline \multirow{2}{*}{ with viscosity-modifying } & $0,20 \%$ & 0,546 \\
\cline { 2 - 3 } admixture & $0,40 \%$ & 0,517 \\
\cline { 2 - 3 } & $0,60 \%$ & 0,536 \\
\cline { 2 - 3 } & $1,00 \%$ & 0,551 \\
\hline
\end{tabular}

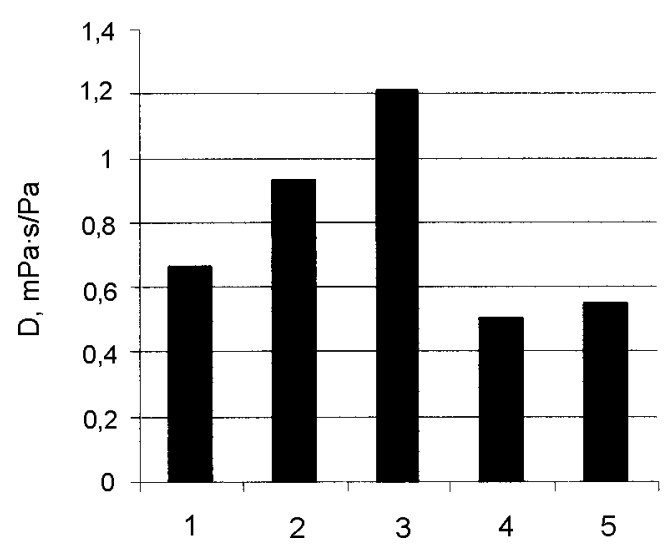

Fig 10. Index of dilatancy D of cement slurries with $1,0 \%$ of admixtures: 1 - without admixture; 2 - with plasticiser (lignosulphonates); 3 - with superplasticiser (polycarboxyl polymers); 4 - with air-entraining admixture; 5 - with viscosity-modifying admixture (synthetic polymers with a big molecular mass)

Fig 10 presents the index of dilatancy of the cement slurries with $1,0 \%$ of admixtures. It shows that the dilatancy of cement slurry is higher with different chemical composition plasticising admixtures, compared with the cement slurry without an admixture. The dilatancy of the cement slurry is much higher with a superplasticiser based on polycarboxyl polymers. The air-entraining and viscosity-modifying admixtures are slightly decreasing the cement slurries dilatancy in comparison to the cement slurry with no admixture.
Chemical admixtures (except for air-entraining and viscosity-modifying admixtures) which are used in practice at the moment, are changing rheologic properties of concrete mixture but they are not improving mixtures flowing in the conditions of increasing shear stress because of its higher dilatancy and so they are not useful for concrete mixture transportation with concrete pumps.

\section{Conclusions}

1. Cement slurries and concrete mixtures are dilatant fluids. The dilatancy of concrete mixtures must be taken in to account in case of usage concrete pumps.

2. Plasticising admixtures with different chemical composition decrease the yield stress and viscosity of cement slurry but they increase the dilatancy of cement slurry.

3. Superplasticisers based on polycarboxyl polymers effective by decrease the yield stress, but significantly increase the cement slurry dilatancy.

4. Air-entraining admixtures result in little reduction of dilatancy of cement slurry and are useful for pumpable concrete.

5. A viscosity-modifying admixture increases the yield stress and stability of cement slurry but has no significant dilatancy reduction effect.

6. The dilatancy of cement slurry and concrete mixture can be estimated by index of dilatancy $D$, ie ratio of change of viscosity to change of shear stress at different shear rates.

\section{References}

1. Kruglickij, N. N. Fundamentals of physical-chemical mechanics. Part 1 (Основы физико-химической механики. Часть I). Kiev: Vishaja shkola, 1975. 207 p. (in Russian).

2. Ovchinikov, P. F.; Kruglickij, N. N.; Michailov, N. V. Rheology of thixotropy systems (Реология тиксотропных систем). Kiev: Naukova dumka, 1972. 120 p. (in Russian).

3. Tang, C. W.; Yen, T.; Chang, C. S.; Chen, K.-H. Optimizing mixture proportions for flowable high-performance concrete via rheology tests. ACI Materials Journal, Vol 98, No 6, 2001, p. 493-502.

4. Pivinski, J. E. Rheology in technology of ceramics and refractories. The basic rules and models of rheology. Refractories (Огнеупоры), No 3, 1994, p. 7-15 (in Russian).

5. Banfill, P. F. G. The rheology of fresh cement and concrete - A Review. In: Proc. of 11th International Cement Chemistry Congress, Durban, May 2003, p. 136-149.

6. Asaga, K.; Roy, D. M. Rheological properties of cement mixes: effects of superplasticisers on viscosity and yield stress. Cement and Concrete Research, Vol 10, No 2, 1980, p. 287-295.

7. Ferraris, Ch. F.; Gaidis, J. M. Connection between the rheology of concrete and rheology of cement paste. $A C I$ Materials Journal, Vol 88, No 4, 1992, p. 388-393. 
8. Aitcin, P. C.; Jiang, S.; Byung-Gi, K.; Nikinamubanzi, P. C. Cement/superplasticizer interaction. The case of polysulfonates. Bulletin des Laboratories des Ponts et Chaussees-233, Ref 4373, 2001, p. 89-99.

9. Sakai, E.; Yamada, K.; Ohta, A. Molecular structure and dispersion-adsorption mechanisms of comb-type superplasticizers used in Japan. Journal of Advanced Concrete Technology, Vol 1, No 1, 2003, p. 16-25.

10. Khayat, K. H.; Saric-Coric, M.; Liotta, F. Influence of thixotropy on stability characteristics of cement grout and concrete. ACI Materials Journal, Vol 99, No 3, 2002, p. 234-241.

11. Khayat, K. H.; Guizani, Z. Use of viscosity-modifying admixture to enhance stability of fluid concrete. $A C I M a-$ terials Journal, Vol 94, No 4, 1997, p. 332-340.

12. Uriev, N. B.; Michailov, N. V. Rheological properties of cement slurries under vibration conditions. Reports of Academy of Science of SSSR. Technical Physics (Техническая физика), Vol 153, No 4, 1963, p. 828-831 (in Russian).

13. Saak, A. W.; Jennings, H. M.; Shah, S. P. The influence of wall slip on yield stress and viscoelastic measurements of cement paste. Cement and Concrete Research, Vol 31, No 2, 2001, p. 205-212.

14. Hu Ch.; De Larrard, F. The rheology of fresh high-performance concrete. Cement and Concrete Research, Vol 26, No 2, 1996, p. 283-294.

15. Lapasin, R.; Papo, A.; Rajgelj, S. Flow behavior of fresh cement pastes. A comparison of different rheological instruments and techniques. Cement and Concrete Research, Vol 13, No 3, 1983, p. 349-356.

16. Ferraris, C. F.; Brower, L. E., editors. Comparison of concrete rheometers: International tests at LCPC. In: NISTIR 6819, Nantes, France, October 2000. 147 p.

17. Ferraris, C. F.; Martys, N. S. Relating fresh concrete viscosity measurements from different rheometers. Journal of Research of the National Institute of Standards and Technology, Vol 108, No 3, 2003, p. 229-234.
18. Williams, D. A.; Saak, A. W.; Jennings, H. M. The influence of mixing on the rheology of fresh cement paste. Cement and Concrete Research, Vol 29, 1999, p. 14911496.

19. Skripkiūnas, G.; Daukšys, M. Investigation of rheological properties and dilatancy of cement slurries. In: Concrete and Reinforced Concrete. Proceedings of conference (Betonas ir gelžbetonis. Konferencijos pranešimų medžiaga). Kaunas: Technologija, 2003, p. 28-35 (in Lithuanian).

20. Daukšys, M. Influence of cement tipe on rheological properties of cement slurries. In: Book of Abstracts of the 5th International Summer School - Conference. Advanced materials and technologies, Palanga, Lithuania, 25-29 August 2003, p. 31.

21. Skripkiūnas, G. Optimization of concrete macrostructure according to its technological and servise properties and raw materials resources (Betono makrostruktūros optimizavimas, atsižvelgiant $\mathfrak{i}$ jo technologines ir eksploatacines savybes bei žaliavų išteklius). $\mathrm{PhD}$ thesis. Kaunas University of Technology, 1993. 185 p. (in Lithuanian).

22. Reiner, M. Deformation, strain and flow. An elementary introduction into rheology (Деформация и течение. Введение в реологию). Moscow: Gostoptechizdat, 1963. 381 p. (in Russian).

23. Kaplan, F. S.; Pivinskij, J. E.; Saprykin, A. N. About features dilatancy of consolidation dispersion of a quartz glass. Journal of Colloidals (Коллоидный журнал), Vol L, No 6, 1988, p. 1092-1098 (in Russian).

24. Curcio, F.; DeAngelis, B. A. Dilatant behavior of superplasticised cement pastes containing metakaolin. Cement and Concrete Research, Vol 28, No 5, 1998, p. 629-634.

25. Ukraincik, V. Study on fresh concrete flow curves. Cement and Concrete Research, Vol 10, No 2, 1980, p. 203-212. 